Proc. Estonian Acad. Sci. Eng., 2003, 9, 4, 252-260

\title{
Plastic flow of BCC metals at monotonous static and dynamic cyclic loading
}

\author{
Antanas Ciuplys ${ }^{\mathrm{a}}$, Jonas Vilys ${ }^{\mathrm{a}}$, Vytautas Ciuplys $^{\mathrm{a}}$, and Valdas Kvedaras ${ }^{\mathrm{b}}$ \\ a Department of Metals Technology, Kaunas University of Technology, 27 Kestucio St, LT-3004 \\ Kaunas, Lithuania; ojvilys@one.lt \\ b Department of Technological Processing, Klaipeda University, 17 Bijunu St, LT-5802 Klaipeda, \\ Lithuania; vgkvedar@takas.lt
}

Received 1 September 2003, in revised form 17 October 2003

\begin{abstract}
This paper deals with the relation between the physical yield plateau and multicycle fatigue disintegration peculiarities. Low carbon steel 20 yield plateau alteration kinetics during the cyclic loading has been investigated. For this purpose samples were loaded cyclically by a fixed load for a number of cycles and after that abruptly statically stretched. It was established that plastic flow of BCC metals on the surface takes place similarly during the monotonous static and dynamic cyclic loading.
\end{abstract}

Key words: metals, mechanical properties, surface layer, cyclic loading, physical fatigue limit, yield plateau.

\section{INTRODUCTION}

The analysis of plastic deformation and failure of metallic materials usually includes such factors as material structure, strain rate, temperature, and others. However, peculiarities of the deformation of the near-surface layers, that in some cases have a significant effect on the mechanical properties and on the mechanisms of plastic deformation and failure, are very seldom taken into account. Partly this situation is related to methodical difficulties and to the limitations of the experimental technique by investigating the fine near-surface layers. Nevertheless, during the last years a series of basic experimental results, using dislocation analysis and modern methods of metal physics, were obtained $\left[{ }^{1-3}\right]$. They explain the peculiarities of the behaviour of the near-surface layer by variable deformation conditions. 
The problem of the plastic yield properties of the near-surface layer during deformation (fatigue, monotonous loading, creep, wear, etc) has a significant theoretical and practical importance. It has been determined that the variation of the characteristics of plasticity and fracture strongly depends on the state of the near-surface layers, their behaviour, and on the environmental effect $\left.{ }^{4-6}\right]$. It has been stated that any theory of strengthening and fracture of metallic materials must take into account surface effects $\left[{ }^{7,8}\right]$. Therefore at present a great attention is paid both to the investigation of near-surface layers of metallic materials and to the methods of their strengthening and modification $\left[{ }^{9,10}\right]$.

In this article the peculiarities of the behaviour of the near-surface layers of a metallic polycrystalline material in the initial stages of plastic deformation during static and cyclic loading are analysed. Some peculiarities of the plastic behaviour of the near-surface layers during monotonous and cyclic deformations are considered. The aim is to define their possible influence on the regularities of evolution of the damage accumulation and on the peculiarities of the metal and alloy behaviour during deformation. Most effectively these peculiarities appear in metals and alloys with the BCC lattice $\left[^{11}\right]$.

A distinguishing peculiarity of BCC metals and alloys is that during their deformation such phenomena as physical yield strength, sharp threshold of cold brittleness, and physical limit of endurance, appear. These phenomena are interrelated. Indeed, even in the absence of direct correlation between the values of the yield strength and endurance limit, it is possible to confirm that there is a lot of common in the nature of these phenomena.

\section{EXPERIMENTAL}

We shall consider the relation between the physical yield plateau and multicyclic fatigue disintegration in the BCC metal. The kinetics of the yield plateau alteration of the carbon steel 20 during cyclic loading has been analysed.

The composition of steel 20 is shown in Table 1.

From a sheet of steel 20 (sheet thickness $1.2 \mathrm{~mm}$ ) samples were cut out, which were annealed within $90 \mathrm{~min}$ at $875^{\circ} \mathrm{C}$. Investigation of the microstructure of the samples showed that during annealing grains of equal axes with an average diameter of $35 \mu \mathrm{m}$ were formed. After machining the samples were mechanically polished. In order to remove residual stress, which appeared after polishing, the samples were annealed in vacuum $\left(10^{-4} \mathrm{~mm} \mathrm{Hg}\right)$ at $550^{\circ} \mathrm{C}$ during $2.5 \mathrm{~h}$. The mechanical properties of the samples after this treatment are shown in Table 2.

The form and dimensions of the samples are shown in Fig. 1.

Table 1. Chemical composition of steel 20

\begin{tabular}{c|c|c|c|c|c|c}
\hline $\mathrm{C}$ & $\mathrm{Si}$ & $\mathrm{Mn}$ & $\mathrm{Cr}$ & $\mathrm{P}$ & $\mathrm{S}$ & $\mathrm{As}$ \\
\hline 0.18 & 0.2 & 0.45 & 0.15 & 0.035 & 0.040 & 0.08
\end{tabular}


Table 2. Mechanical properties of steel 20

\begin{tabular}{c|c|c|c|c}
\hline $\begin{array}{c}\text { Tensile strength } \\
R_{\mathrm{m}}, \mathrm{MPa}\end{array}$ & $\begin{array}{c}\text { Yield strength } \\
R_{\mathrm{e}}, \mathrm{MPa}\end{array}$ & $\begin{array}{c}\text { Elongation } \\
A, \%\end{array}$ & $\begin{array}{c}\text { Contraction } \\
Z, \%\end{array}$ & $\begin{array}{c}\text { Fatigue limit } \\
\sigma_{\mathrm{R}}, \mathrm{MPa}\end{array}$ \\
\hline 395 & 240 & 25 & 37 & 220
\end{tabular}

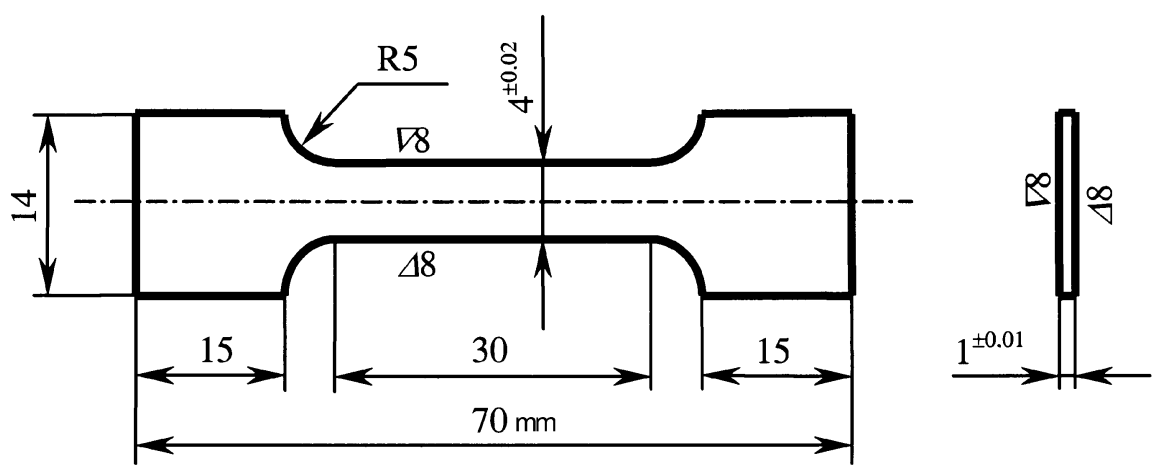

Fig. 1. Sample for static and cyclic loading.

The tests of cyclic tension fatigue were carried out with a loading frequency of 2800 cycles/min with a Shenk type pulsator at the stress $\sigma=230 \mathrm{MPa}$.

In order to investigate alteration kinetics of the yield plateau during cyclic loading, part of the samples were after a number of cycles taken out of the pulsator and immediately statically stretched in a universal tension machine Instron. Static tension tests were carried out at $2.78 \times 10^{-3} \mathrm{~s}^{-1}$. Having performed the tests, it was established that with such a deformation velocity maximal yield plateau length was obtained. The lengthening of the deformation axis was recorded in the scale of 200:1; this allowed to determine exactly the length of the yield plateau and other tension curve parameters. Mechanical properties of the steel 20 have been determined by stretching annealed samples. In the tension curve the yield peak and the yield plateau can be clearly distinguished. The yield was $2.6-2.8 \%$ of the annealed samples.

In Figs. 2 and 3 experimental data, obtained by investigating the length alteration kinetics and shape of the yield plateau as well as the variation of the proportionality limit are shown. From Figs. 2 and 3 it follows that the cyclic load, after some incubation period (which at the load $230 \mathrm{MPa}$ is equal to $\cong 10$ cycles) causes disappearance of the yield point. When number of the cycles increases, the yield plateau shortens until total disappearance. However, until the disappearance of the yield plateau, the load at which it appears remains the same. Together with the disappearance of the yield plateau a decreasing of the proportionality limit was observed (Fig. 4). However, when during the cyclic loading the Liuders-Chernov front passes through the whole testing length, the proportionality limit increases again almost until the initial value. 


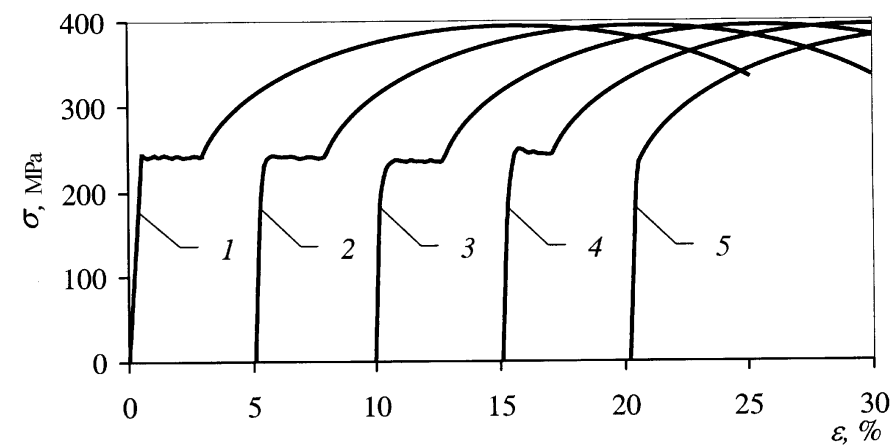

Fig. 2. The $\sigma-\varepsilon$ curves after cyclic loading $(\sigma=230 \mathrm{MPa})$ : $1-$ annealed sample; $2-$ after $10^{2}$ cycles; 3 - after $8 \times 10^{2}$ cycles; 4 - after $3 \times 10^{3}$ cycles; 5 - after $1.8 \times 10^{4}$ cycles.

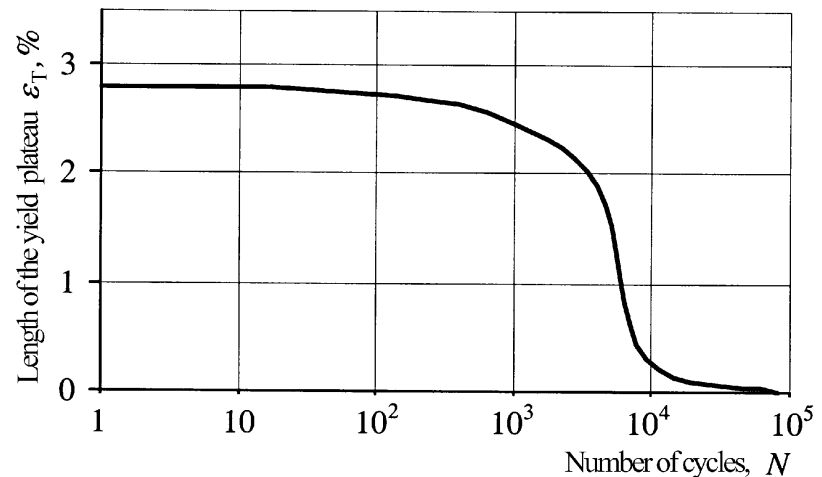

Fig. 3. Alteration of the length of the yield plateau by cycling loading ( $\sigma=230 \mathrm{MPa})$.

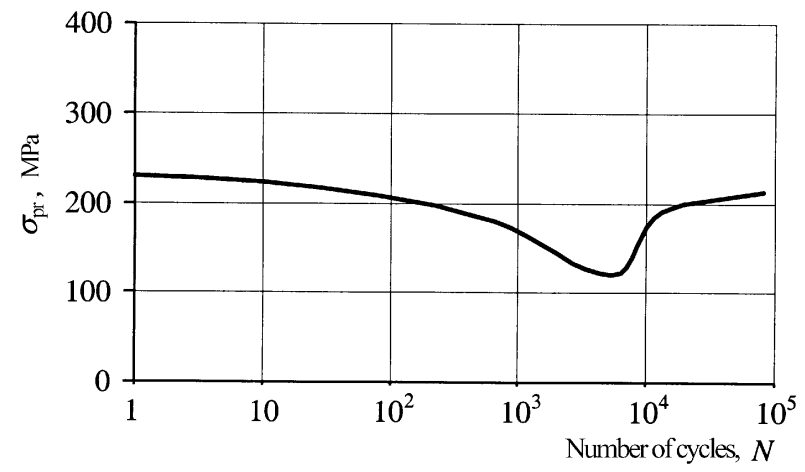

Fig. 4. Alteration of the proportionality limit by cycling loading ( $\sigma=230 \mathrm{MPa})$.

Experimental data on the kinetics of the Liuders-Chernov front expansion for various cyclic loads are given in Figs. 5 and 6. 


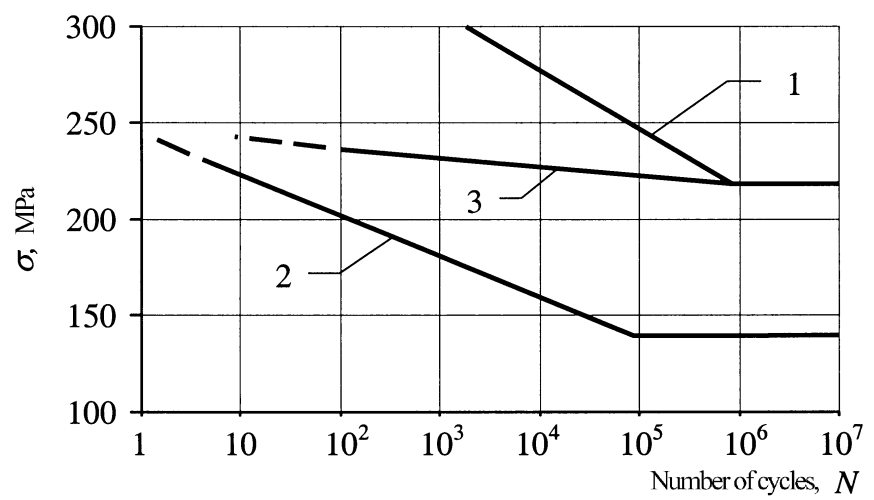

Fig. 5. The diagram of fatigue of the annealed steel 20 samples: 1 - fatigue curve; 2 - LiudersChernov front expansion start line during cycling loading; 3 - Liuders-Chernov front termination line.

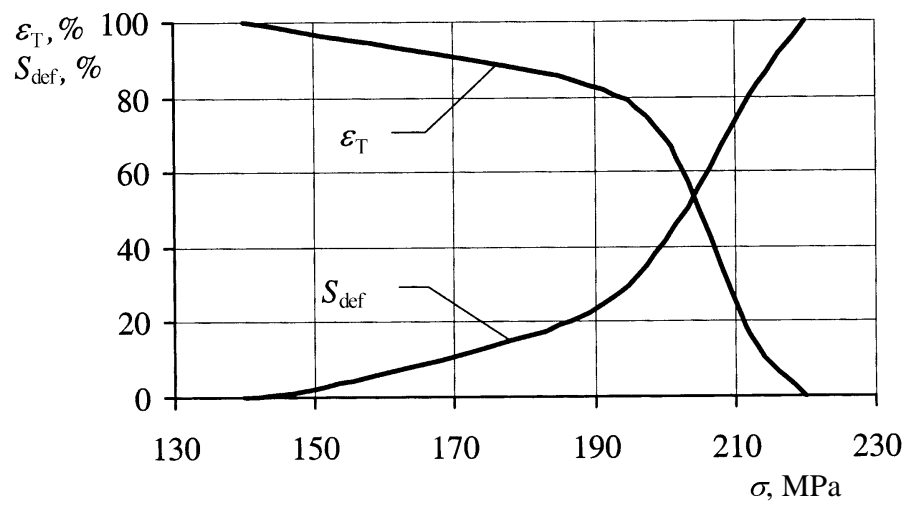

Fig. 6. The kinetics of macroscopic deformation accumulation when load is less than the fatigue limit: $\varepsilon_{\mathrm{T}}$ - length of the yield plateau after cyclic loading; $S_{\text {def }}-$ Liuders-Chernov front expansion area over the surface of the sample.

Curve 2 in Fig. 5 corresponds to the start and termination of the incubation period when no changes in the yield plateau length has occurred. Curve 3 corresponds to the termination of the Liuders-Chernov front. It should be noticed that for the first time such an incubation period for metals with a yield plateau and physical fatigue limit was observed in $\left[{ }^{12}\right]$ where the kinetics of the variation of the yield limit by tension-pressure fatigue was investigated. In our case (cyclic tension), in contrast to the tension-pressure case, the Liuders-Chernov passing period is elongated.

Thus the analysis of the obtained results leads to the conclusion that by cyclic tension or tension-pressure, the physical fatigue limit corresponds to such a critical tension at which the Liuders-Chernov front may still pass through the whole sample length. 
However, in contrast with paper $\left[{ }^{12}\right]$ we have determined that by cyclic tension even less than the fatigue limit, after some incubation period the macroscopic deformation starts (Figs. 5 and 6). When the tension is less than the fatigue limit (but not less than $140 \mathrm{MPa}$ ), during the cyclic loading the LiudersChernov front does not pass through the whole working length of the sample but stops at an instant. The quantitative data on the Liuders-Chernov front expansion kinetics during cycling loading (tension) less than the fatigue limit are given in Fig. 6. For example, when the cyclic load is equal to $180 \mathrm{MPa}$ (i.e., $40 \mathrm{MPa}$ less than the fatigue limit), the Liuders-Chernov front covers only $20 \%$ of the sample surface. When the load is $140 \mathrm{MPa}$, macroscopic deformation is not observed. The obtained data about the yield plateau variation during cyclic loading and the earlier expressed hypothesis about the character of the yield plateau and fatigue limit processes $\left[{ }^{12}\right]$ allow to elucidate the processes, which take place during cyclic loading in metals with a physical yield plateau.

When the tension is equal to the fatigue limit, then already with the first loading cycle macroplastic deformation of the surface starts, which during the whole incubation period strengthens only the surface layer (approximately of grain size depth). Strengthening takes place due to the increase of the dislocation thickness and dynamic deformation of aging $\left[{ }^{13,14}\right]$. It should be noted that during the incubation period the macroplastic deformation (about $10^{-3} \%$ ) may be noticed already after the first cycle and in the whole cross-section of the sample $\left[{ }^{12}\right]$.

Thus during the whole incubation period of the fatigue an intensive plastic deformation of the metal surface and slight microplastic deformation within the whole cross-section of the sample takes place.

Due to the difference in the deformation of the surface and internal layers and also to the dynamic deformation aging processes, at the end of the incubation period the formation of a firmer surface layer begins. When the number of cycles, which corresponds to the end of the incubation process, has been reached, a local break through the surface layer occurs and macroscopic deformation through the whole cross-section of the sample starts. As a result, during cyclic loading the Liuders-Chernov front passes through the whole working length of the sample. The passing kinetics of the Liuders-Chernov front during cyclic tension is the same as during the static deformation (macroscopic flow usually starts from the sample head). However, in the surface layer of the metal increased dislocation thickness in comparison with the dislocation thickness in internal metal layers remains. This happens due to the increased deformation of the surface grains and due to the fact that the surface layers even now generate more dislocations.

Continuing cyclic loading further on, when the load becomes equal to the fatigue limit, macroscopic deformation accumulation through the whole sample volume was observed. The aging processes of dynamic deformation are also rather intensive $\left[{ }^{15}\right]$. On the metal surface microcracks may form with a size not bigger then one grain $\left[{ }^{16}\right]$.

The metal surface layer becomes gradually strengthened by enlarged blocking dislocation density when the number of cycles reaches a certain value. At this 
time the microcracks inside some grains can be observed, but they do not develop into fatigue cracks at any number of cycles. Microcracks do not reach the critical size, because they are not larger than one grain $\left[{ }^{17-20}\right]$. This critical tension, at which such a strengthened surface layer is formed, corresponds to the materials physical fatigue limit.

Thus in the presented model the physical fatigue limit is related to the increased surface layer formation (about a grain depth size) at any cyclic loading independently of the character of loading. Fatigue limit corresponds to such a tension at which critical microcracks in the strengthened surface layer have not appeared yet.

Such a surface layer of the material has greater strength in comparison with internal layers. This layer serves as a barrier for dislocations which come from the internal layers and at the same time prevents appearance of irreversible breaks.

It should also be noticed that for annealed low-carbon steel the fatigue limit is sometimes a little bit greater than the static yield limit. However, even after a considerable macroscopic deformation in the thin surface layer and in internal layers some difference of the deformations remains. During the cyclic loading, when the load is equal to the fatigue limit, an intensive dynamic deformation aging causes blocking of the dislocation $\left[{ }^{21}\right]$. In the metal surface layers a greater dislocation thickness remains and this prevents the appearance of the fatigue cracks.

The described hypothesis about the physical fatigue limit explains in a more simple way the appearance of the fatigue limit by deformation of metals and alloys with BCC lattice of simple carbon steels. In these steels the appearance of the evenly strengthened surface layer stipulates the fact that during the static and cycling loading the plastic deformation starts in the thin surface layer (of about grain size depth). This is influenced by two factors: great amount of sliding systems and the intensive aging by deformation. This investigation also shows that plastic deformation in the metal surface layer takes place similarly during static and cyclic loadings.

\section{CONCLUSIONS}

1. Plastic flow of BCC metals at static and cyclic deformation in the surface and internal layers takes place in different ways.

2. By static tension of dynamically deformed samples the length of the yield plateau depends on the number of cycles. load.

3. The Liuders-Chernov front expansion during cyclic loading depends on the

4. Plastic deformation in the surface layer of the BCC metals is similar at monotonous static and dynamic cyclic loading. 


\section{REFERENCES}

1. Hirth, J. P. Some current topics in dislocation theory. Acta Mater., 2000, 48, 93-104.

2. Arsenault, R. J. and Hsu, R. Operation of near-surface dislocations sources. Metall. Trans., 1982, 7, 1199-1205.

3. Sosnin, O. V., Popova, H. A., Ignatenko, L. N., Konovalov, S. V., Ivanov, Yu. F., Gromov, V. E., and Kozlov, E. V. Evolution of dislocation substructure of steel of $45 \Gamma 17 \mathrm{H} 3$ grade during multi-cycle tests under electric stimulation method. Materialovedenie, 2002, 63, 37-42 (in Russian).

4. Al'okhin, V. P. Physics of Strength and Plasticity of Surface Layers of Materials. Nauka, Moscow, 1983 (in Russian).

5. Wu, C. H., Hsu, J., and Chen, C. H. Effect of surface stress on the stability of surfaces of stressed solids. Acta Mater., 1998, 46, 3755-3760.

6. Zernin, M. V. A finite-element description of the fatigue process with allowance mode of the specific properties of the material surface. Zavodskaya Laboratoriya, 1995, 61, 43-51 (in Russian).

7. Kramer, I. R. Surface layer effects on the mechanical behaviour of metals. Adv. Mech. Phys. Surface., 1986, 3, 109-260.

8. Kolmakov, A. G., Terentjev, V. F., and Gerov, V. V. The effect of the surface state of metal wires on their mechanical properties. Metallovedenie i Termicheskaya Obrabotka Metallov, 2002, 8, 33-38 (in Russian).

9. Tarley, D. M. and Doyle, E. D. The importance of surface characterization in surface treatment. Wear Proc., 1982, 81, 145-158.

10. Burke, J. J. Surface Treatments for Improved Performance and Properties. Mir, Moscow, 1985 (in Russian).

11. Vilys, J., Čiuplys, V., Čiuplys, A., and Kvedaras, V. Influence of surface layer squeezing on the mechanical properties of metals. Materials Science. Medžiagotyra, 2002, 8, 14-19.

12. Gurjev, A. V. and Stolyarov, G. Yu. Materials Science and Strenght of Materials. Volgograd Politechnical Institute, Volgograd, 1968 (in Russian).

13. Firstov, S. A. and Pechkovskij, E. P. Vicissitude of strain hardening of polycrystals. Voprosy Materialovedeniya, 2002, 29, 70-86 (in Russian).

14. Vakulenko, I. A. and Razdobreev, V. G. Strain hardening of low-carbon steel in the field of microyield. Metally, 2002, 2, 100-102 (in Russian).

15. Rybakova, L. M., Bulytchev, S. I., Tumasyan, V. S., Kuksenova, L. I., and Al'okhin, O. V. Aging by deformation in surface layers low carbon steel. Metallovedenie i Termicheskaya Obrabotka Metallov, 1990, 11, 32-38 (in Russian).

16. Terentjev, V. F. Fatigue of Metallic Materials. Nauka, Moscow, 2002 (in Russian).

17. Nakaima, K., Urabe, T., Hosoya, Y., et al. Influence of microstructural morphology and prestraining on short fatigue crack propagation in dual phase steels. ISIJ Internat., 2001, 41, 298-304.

18. Tanaka, K. and Akiniwa, Y. Small fatigue cracks in advanced materials. In Proc. Sixth International Fatigue Congress, 1996, vol. 1, 27-38.

19. Shiozawa, K., Ohtani, T., Nishino, S., et al. Fatigue strength and subsurface crack growth properties of plasma assisted duplex surface treated tool steel. Trans. Jap. Soc. Mech. Eng., 1998, 628, 3050-3057.

20. Pinyak, I. S. Micro- and macrorates of fatigue crack propagation in steels and alloys under the influence of crack closure. Problemy Prochnosti, 2002, 355, 88-101 (in Russian).

21. Khannanov, Sh. Kh. Collective effects in the system of bounded dislocations. Fizika $i$ Khimiya Obrabotki Materialov, 2002, 3, 60-65 (in Russian). 


\title{
Ruumkeskendatud kuupvõrega metallide plastne voolamine monotoonsel staatilisel ja dünaamilisel tsüklilisel koormamisel
}

\begin{abstract}
Antanas Ciuplys, Jonas Vilys, Vytautas Ciuplys ja Valdas Kvedaras
On käsitletud materjalide füüsikalise voolavusplatvormi ja multitsüklilise väsimuspurunemise vahelist seost. Uuriti madalsüsinikterase voolavusplatvormi muutumise kineetikat tsüklilisel koormamisel. Etteantud tsüklite arvu juures koormatud teimikud purustati staatilisel koormamisel. Selgitati ruumkeskendatud kuupvõrega metallide plastse voolamise sarnasus monotoonsel staatilisel ja dünaamilisel tsüklilisel koormamisel.
\end{abstract}

